\title{
Cultural/Social Media Space of the Digital Generation
}

Dinara R. Saparova, ${ }^{* *}$ Almagul M. Kanagatova, ${ }^{*}$ Albina S. Zhanbosinova, ${ }^{\hat{\imath}}$ and Yelena Y. Chzhan ${ }^{\hat{\imath}}$

\section{Abstract}

Taking the example of Kazakhstan, this study examines the formation and analysis of the cultural media space of the digital generation. Information and communication technologies are the basis of a communicative media environment that has an internal regulated structure, which affects the socialisation of a person. The content of the cultural media space of the digital generation is formed on the basis of digital technologies and represents people's visual worldview with images, signs and symbols.

The processes of transformation of society affect the young generation and the content of the media space that determines their social and ethnocultural identity. The study presents the results of working with schoolchildren and students aged 14-18 using focus groups to explore the impact of digital culture (media culture) on adolescents in Kazakhstan. Based on the interdisciplinary approach, the findings demonstrate intergenerational contradictions because of the active involvement of Kazakhstan in the global internet community. The cultural media space of Kazakhstan has been shaping the social communications of the digital generation that has grown up in a sovereign state. The theoretical concepts of P. Bourdieu, C. Mannheim and other scientists served as a methodology for this study. Based on the interdisciplinary approach, the findings demonstrate intergenerational contradictions because of the active involvement of Kazakhstan in the global internet community. The findings also unravel that the transformation of the value orientations of adolescents is influenced by the factors of geographical location and ethnicity.

Keywords: Digital Generation; Communications; Media Space; Social Platform; Kazakhstan

\footnotetext{
${ }^{+}$Al-Farabi Kazakh National University, Kazakhstan

${ }^{*}$ Corresponding Author, Email: dinara.saparova.79@list.ru, dinarasap@mail.ru

¥ Almaty University of Management, Kazakhstan, Email: almagul.kanagatova@almau.edu.kz

î S. Amanzholov East Kazakhstan State University, Kazakhstan, Emails:zhanbossinovaa@gmail.com; elena_zhang@mail.ru

(C) 2020 Saparova et al. This is an Open Access article distributed under the terms of the Creative Commons Attribution License (http://creativecommons.org/licenses/by/2.0), which permits unrestricted use, distribution, and reproduction in any medium, provided the original work is properly cited.
} 


\section{Introduction}

Modern society lives in an era of innovative information technologies. The modern dynamic world with mass access to internet resources has created a new type of person with special communicative connections in the conditions of personal digital space. The uniqueness of the current time lies in shifting accents, where the primary trend is seen in a smooth transition "from team and discipline to individual freedom, from group norms to individual diversity, from state power to personal independence, which gives rise to self-expression values" (Inglehart \& Welzel, 2011: 12-13).

Information technology has formed a different space following the needs of the digital generation. This phenomenon is studied by psychologists and educators around the world (Bolin, 2016). The research uses an interdisciplinary approach, in the interweaving of disciplines such as sociology, psychology, history, culture, anthropology, where the object of the study is the cultural media space, and the subject is "digital generation" or "generation Z" (define generation $Z$ with reference in footnote). 1 out of 6 billion of the world's population with access to digital technologies (the internet) are designated as "tribe", "population" (Godik, 2011). Scientists have revealed the failure of communicative generational ties - the elderly people do not accept the virtual world, while the younger ones do not recognise themselves without it. The purpose of the study is to analyse the content of the cultural (social) media space of the digital generation in Kazakhstan.

Methodological research approaches are developed at an interdisciplinary level. These approaches allow us to understand online media space and its impact on the environment (Carstensen, 2015: 284-302).

Gadgets have replaced traditional kids' games. This study attempts to underline the influence of digital games on child and childhood and explore the appropriateness of growing up with ICT and gadgets (Nair, 2016: 79-92). There is an opinion that: "...online technology is tailor-made for searching for information rather than analysing complex ideas..." (Baron, 2017: 15-20).

An analytical review of the online content of the cultural media space has revealed a significant role of non-profit organisations, museums, educational and government institutions. The unique interactive features of the internet allow large companies to integrate advertising and website content to promote "brand awareness" and "brand loyalty" among children, encouraging them to become consumers from a very young age. Demand determines the quality of the content of websites that promote the education and development of children, the formation of the foundations of citizenship and responsibility in children (Montgomery, 2000: 145-167). It makes sense to adapt the media space to a learning environment of the digital generation, to encourage students in the framework of school activities (Duncum, 2015: 43-53). There is an experience in integrating social networks into music education classes, which facilitates the learning process (Albert, 2015: 31-38). At the same time, there is a danger of the influence of media communications on the structure of human experience, the structure of subjectivity, methods of identifying an individual.

The content of the cultural media space is subject to the influence of destructive forces, such as anonymous portals, radical Islam, pornography and many others. (Popovkin \& Popovkina, 2019; Shehabat et al., 2017; Shehabat \& Mitew, 2018). Two approaches to the study of the digital generation are distinguished. The first approach involves "toxic childhood", young people are obsessed with computer games and do not show interest in real life. The second approach marks new opportunities for the digital generation (Green \& Hannon, 2007).

This study begins with a description of the methods employed for the study. Following this, it critically discusses the results of the study. 


\section{Methods}

The study is based on the theoretical concepts of structural constructivism, namely, P. Bourdieu's provisions on the social space, where the media are the agents of content formation (Bourdieu, 2005). The analytical theories of Parsons (2002) and Luhmann (2005) revealed the multifaceted nature of cultural media space

The works of K. Mannheim focused on generational differences; on the style of thinking of different age groups from the same era (Mannheim, 2000). The anthropological approach of $\mathrm{M}$. Mead revealed the cultural practices of communications. The Kazakhstan community is at the stage of development of a prefigurative culture (Jussupov, Bozhkarauly \& Rustembekova, 2018). The contradiction is expressed in various generational practices of social adaptation and communication. Some relate to the past, while other - to the present and future (Mead, 1983).

The theoretical and practical basis of the article includes the following:

- results of a sociological survey;

- analysis of philosophical, pedagogical and psychological literature;

- survey methods (questionnaire, interview, the test of L. Pochebut on the basis of the theory of F. Kluckhohn, F. Strodtbeck) (Pochebut, 2012: 245).

Data have been processed using the SPSS programme.

The sociological study has been conducted to determine the impact of digital culture (media culture) on modern adolescents in Kazakhstan. The target group includes schoolchildren and students of Kazakhstan aged 13-18 years. For the research tools, an anonymous questionnaire with 27 questions were distributed among the secondary schools of Almaty, Karaganda, Pavlodar, Shymkent, Kyzylorda, Aktobe, Semey, and Ust-Kamenogorsk. The survey was conducted in 2018-2019. In the geographical aspect, the north, south, east and west of Kazakhstan are represented. As a percentage, urban respondents have accounted for $83 \%$, rural for $16 \%$.

In the cities of Ust-Kamenogorsk (as a regional city) and Almaty (of republican significance), the focus group method has been used. Interviews were conducted with four groups of 9-11 grades from East Kazakhstan and Almaty region, among rural and urban youths pursuing Russian and Kazakh languages.

Separate interviews were held with one Kazakhspeaking group of students of 9-11 grades from the city of Ust-Kamenogorsk; two groups from each region- rural and urban youth with Russian and Kazakh study languages. The questionnaire was conditionally divided into blocks:

- Social portrait of respondents (questions1-7);

- The Internet and generation Z (questions 8-12 and question 19);

- Social networks and adolescents (questions 13-27).

The social portrait of the respondents is as follows: only 370 respondents have participated in the survey, out of which $57 \%$ are females and $43 \%$ are males. Ethnic characteristics of the respondents are as follows: $63 \%$ - Kazakhs, $20 \%$ - Russians, 4\% - others (Uyghur, Korean, Karakalpak, Chechen, Mongolian, Uzbek, and Ukrainian). Schoolchildren and college students aged 13 to 18 have been the respondents, identifying themselves as representatives of the new generation $Z$ (Table 1 ). 
Table 1: The Age of the Respondents

\begin{tabular}{|l|l|}
\hline 13 years old & $1 \%$ \\
\hline 14 years old & $7 \%$ \\
\hline 15 years old & $19 \%$ \\
\hline 16 years old & $42 \%$ \\
\hline 18 years old & $23 \%$ \\
\hline
\end{tabular}

Source: Created by the Authors

\section{Results}

This study investigates the formation and analysis of the cultural media space of the digital generation in Kazakhstan. Among the interviewed adolescents, there have been predominantly school pupils (98\%) and only $2 \%$ were students of colleges and universities of the country.

The answers to the question "Who do you live with? (complete/incomplete family, with grandparents, alone, other)" demonstrate that $85 \%$ live in a complete family, $17 \%$ - in an incomplete family (either father alone or mother alone) and $4 \%$ live only with their grandmother.

Analysis of the results of the survey's second block - "Internet and Generation Z", in the focus of historiography of the problem, has allowed the researchers' to identify the criteria for the media space of adolescent respondents.

The first criterion is the space-time criterion, which is described by a slogan: "I am a cosmopolitan"; "I am a unique personality", "Generation Me - Generation We model".
Information is not limited by borders or time. Representatives of Generation Z are in different communities, try on different personalities, and show interest in different areas of life (Sparks \& Honey, 2015: 46).

The environment of the teenager in Kazakhstan is represented by a game, whose actors are people, regardless of race, religion, gender orientation, location and language, who interact in social networks, instant messengers, and internet platforms. The study shows round-theclock ability to use internet resources, both from home internet ( $65 \%$ of respondents) and mobile internet (62\%).

The internet is the main source of information about politics, economics, events in the world, etc. for modern adolescents, according to 321 respondents (87\%). It is worth noting that $27 \%$ received information from television, while the percentage of the respondents receiving information via conversations with family and friends stand respectively at $21 \%$ and $14 \%$ (Figure 1).

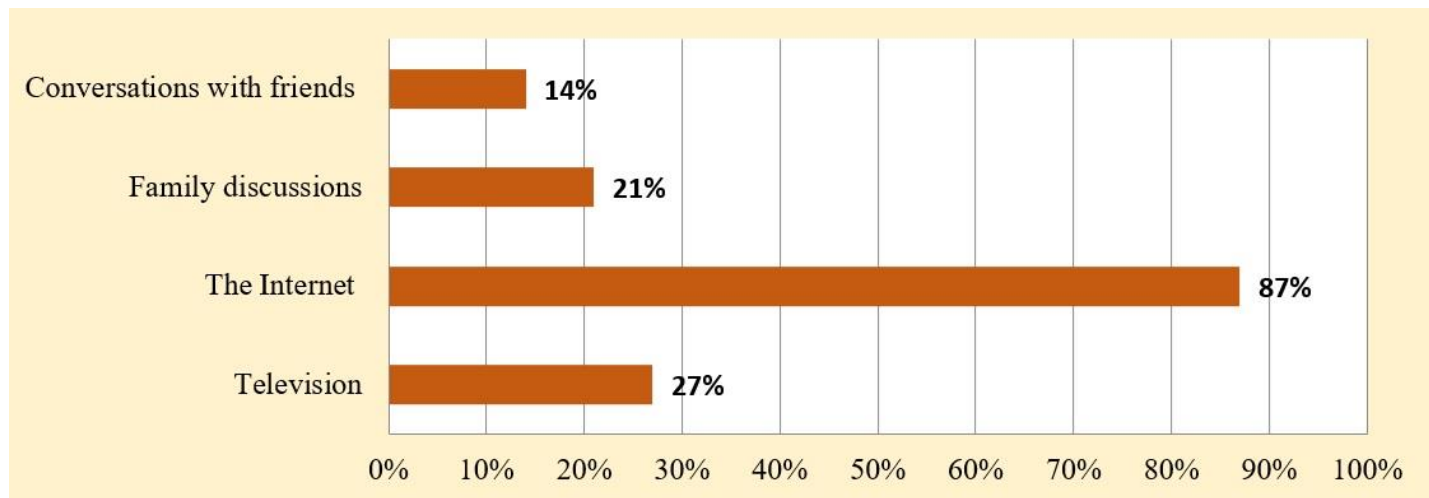

Figure 1: Sources of Information Source: Created by the Authors

1 Although the term 'family' is highly contentious in academic usage, for the sake of this research, we use it as members living in a household with wife, husband and children (Bhattacharyya, 2009). 
Access to school internet has been noted by only $9 \%$ of the respondents and only three students have noted that they lack the ability to use the Internet. The environment is defined by "technological determinism" (Mesch, 2009: 50). New technologies easily satisfy the teenager's need to be heard, to have friends, to find his/her place. One can access the whole media world while being in a bedroom (Mesch, 2009: 53), one can shop, work, study, communicate, participate in political, economic, cultural discussions, comment on events and create posts.

In the focus groups discussions, the researchers' identified the tendency of adolescents to meet with their peers in their free time in places of large crowds of people (with internet access) where they have all the opportunities to fulfil their needs. These places include shopping centres, malls, in which one can do shopping, drink coffee and have free internet access that enable them to interact and post in social networks (Vkontakte, Instagram) about the activities that they engage themselves at that moment, for example, the kind of food they eat; the kind of goods they buy, and many others. Reality and virtuality are on the same plane. $60 \%$ of urban teenagers have indicated that they prefer to meet in Mega-centre in Almaty, McDonalds or Starbucks. The researchers' observations have shown that spending time in such centres makes them a part of the society, global world. After all, there are Starbucks, burger centres, brand boutiques, such as 'Zara' everywhere across the globe, and in this sense, the teenagers from major cities of Kazakhstan are not that different from those in Germany, America or Russia.

Such places equalise and unite people (Oldenburg, 1999: 67). A teenager feels the freedom of action and equality.

One of the motives for using the internet is the speed of obtaining and processing information. $94 \%$ of schoolchildren, in preparation for lessons, access the internet in order to quickly find a solution to the problem. $76 \%$ respondents reckoned that the function of emoji (graphic images expressing emotions) on social networks reduces the time it takes to send a message.
Being a part of the global world, Kazakhstan teenagers (mostly urban population) prefer the web content in Russian, which makes it possible to "get more information", "have free access to information". Although, in recent years, the demand for Kazakh-language content has increased, the urban population prefers both Russian-language and Kazakh-language content ( $60 \%$ and $40 \%$ respectively); while for the rural population, it depends on the contingent living in the village.

Thus, in the East Kazakhstan region, research has been conducted in Russian-speaking settlements and villages (here, the content is $100 \%$ Russian), in Almaty region (50\% to $50 \%$ ). $100 \%$ of all surveyed teenagers use English, for a better perception of the English-language content on which the global internet is based today. An interesting observation has been made when comparing two groups of teenagers (Kazakhspeaking and Russian-speaking). Russianspeaking adolescents perceive themselves as "global citizens"; Kazakh-speaking adolescents "as a part of their family, of their state". Accordingly, a Russian-speaking adolescent mainly respects (and perceives as a role model) either him/herself or a similar teenager who has achieved great results in some activity. While a Kazakh-speaking teenager most likely respects and obeys his/her family, most often the mother, father or elder brothers or sisters. That is explained by the degree of influence of traditional family values of the Kazakh society, the memory frame. Russian-speaking adolescents are affected by Russian-language content, a pro-Western model of cultural development.

Researchers have formed the model 'Generation Me - Generation We' (Owen, 2018). On the one hand, a teenager is an autonomous, selfsufficient, independent person, on the other hand, this generation is of "sociopaths" who are afraid, but need to realise themselves in society. Modern teens are deeply insecure people, who constantly try to find themselves and be useful to society. That is why they are so keen on volunteering. $50 \%$ of the adolescents have responded that they are interested in volunteer 
work that can benefit people. In social networks, a teenager seeks the practice of socialisation, tries him/herself in different roles. In 2018, the researcherss have interviewed Askhat Abzhanov, the young founder of the 'New Generation' Centre (Zhana urpakh, 2017). According to 'The Gen Z equation' study by Sarah Owen (Owen, 2018), in 2016, 13-year-olds, who spent more than 10 hours a week in social networks had a $56 \%$ chance of being unhappy, while $27 \%$ of users of social networks showed an increased risk of depression. "On social media, it is all about being popular, pretty and fake. In real life, it is not abot being rich or pretty or whether one wears makeup, there are chores to do and everyday life stuff. In everyday life, you'll take a stroll, but in electronic life you'll take a scroll. Paris, 15, Brisbane, Australia" (Owen, 2018: 5).

The second criterion is digital identity (virtual and real identity, self-identity construction).

In this digital age, children spend most of their lives on the internet and make no distinction between life on the web and the real life. They do not perceive identity in digital and real space as something separate; they believe that their identity is represented in several spaces at once (Palfrey \& Gasser, 2011).

Without making a distinction between virtuality and reality, they prefer to live in the former one. Teenagers have multiple accounts in social networks. The most popular networks are Vkontakte, Instagram, and then YouTube video platform. In the first network, they listen to music and communicate via messenger. In Instagram, they are interested in the lives of other people, as well as brands of goods, cosmetics, etc. On the YouTube platform, they are attracted by the visuals, videos, which they can comment on, and most importantly, create their own account for public viewing. From the age of five, children watch challenges on YouTube, the main actors of which are their peers.

Active use by the youth of social platforms Vkontakte, Instagram, Telegram, etc. constructs the image that a teenager wants. The change of communication in the space-time context allows individuals to construct their own images, the ones they want. The researchers note some of the respondents' statements:

In social networks, I feel confident, because nobody can see me or I can create my page and add friends, or delete friends, decide by myself whether to communicate with them or not.

Much that I cannot tell my parents, I can write to social networks.

I like to view beautiful people's accounts, watch for their lifestyle. While looking at them, I also try to change.

Transformations occurring in society affect identity. Knowledge in a technoculture becomes transparent, tangible, and people living today in such a culture try both its capabilities and its negative effects (Levy, 1997: 222).

The question "How often do you use the internet?" unfolded that $72 \%$ of the respondents use the internet every hour, the remaining half (24\%) access the internet every 30 minutes. 2 $3 \%$ of students out of all 370 respondents use the internet 2-3 times a week (Figure 2).

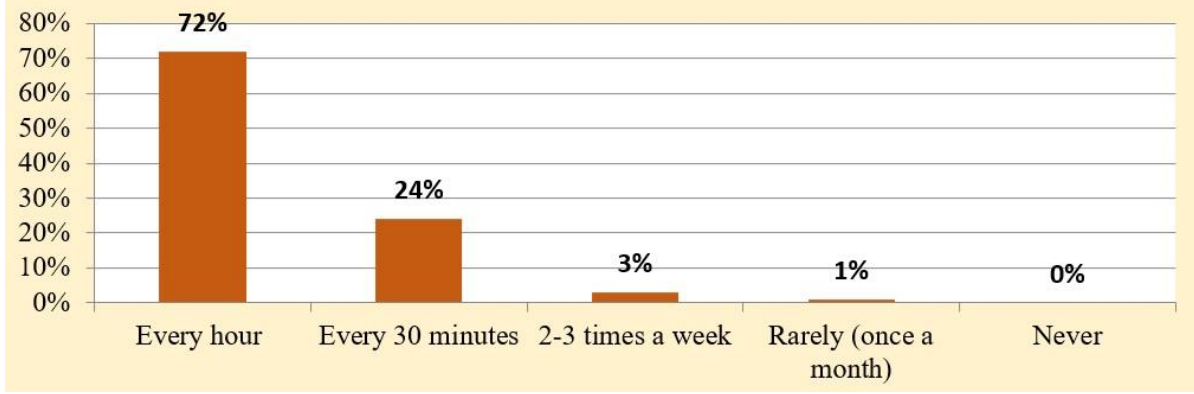

Figure 2. Frequency of Using Internet Resources Source: Created by the Authors 
Free access to the internet has become a familiar and natural phenomenon for the new generation. Most often teenagers use the home internet (65\%) and mobile internet (62\%), only $9 \%$ use school internet, while three students have no internet access. The results indicate the round-the-clock possibility of using internet resources, as well as the possible dependence of adolescents on the latter (Figure 3 ).

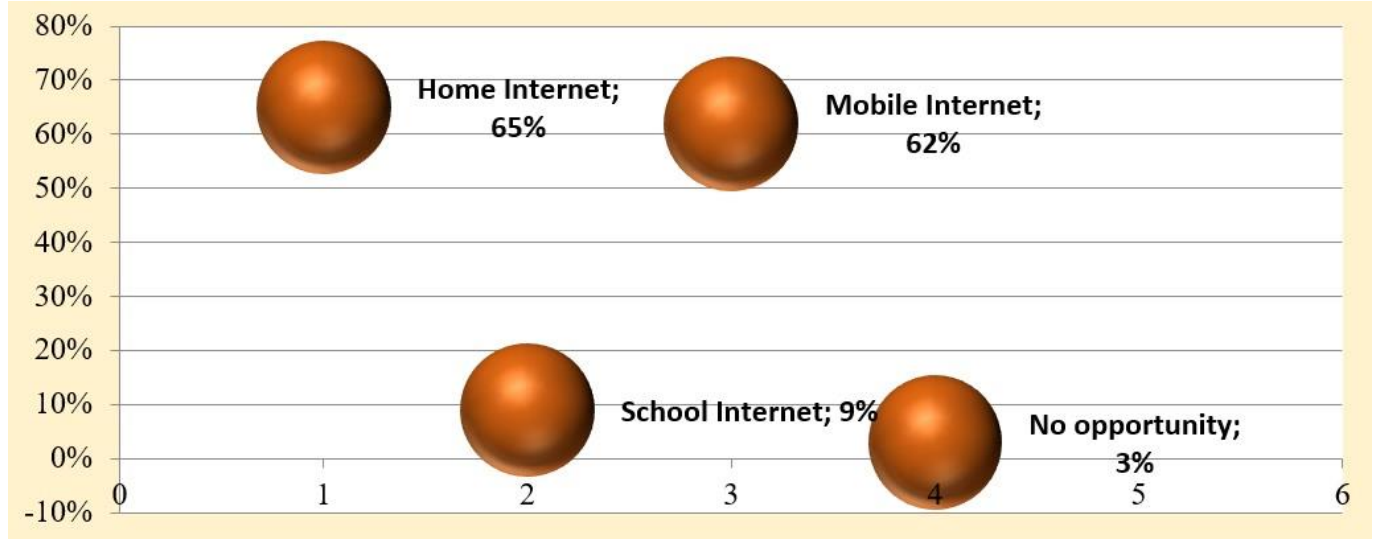

Figure 3. Means of Accessing the Internet Source: Created by the Authors

Social networks are popular among $88 \%$ of the teenagers (Figure 4). Search engines are used by $40 \%$; while $21 \%$ use gaming, entertainment sites. Social networks have a substantial impact on adolescents. This is a kind of vanity fair for likes, the evidence of psychological dependence. There is the virtual world, virtual friendship, everyday virtual life; when all the latter confront the real-life - conflicts and tragedies arise.
Social networks stimulate the emergence of extensive interdisciplinary research practice and the development of programmes to prevent adolescents from dependence on the virtual world. There is a problem of dependence on internet sources. Besides, many aspects reflect psychological defects, such as loss of communication skills or analytical thinking, isolation in oneself, etc.

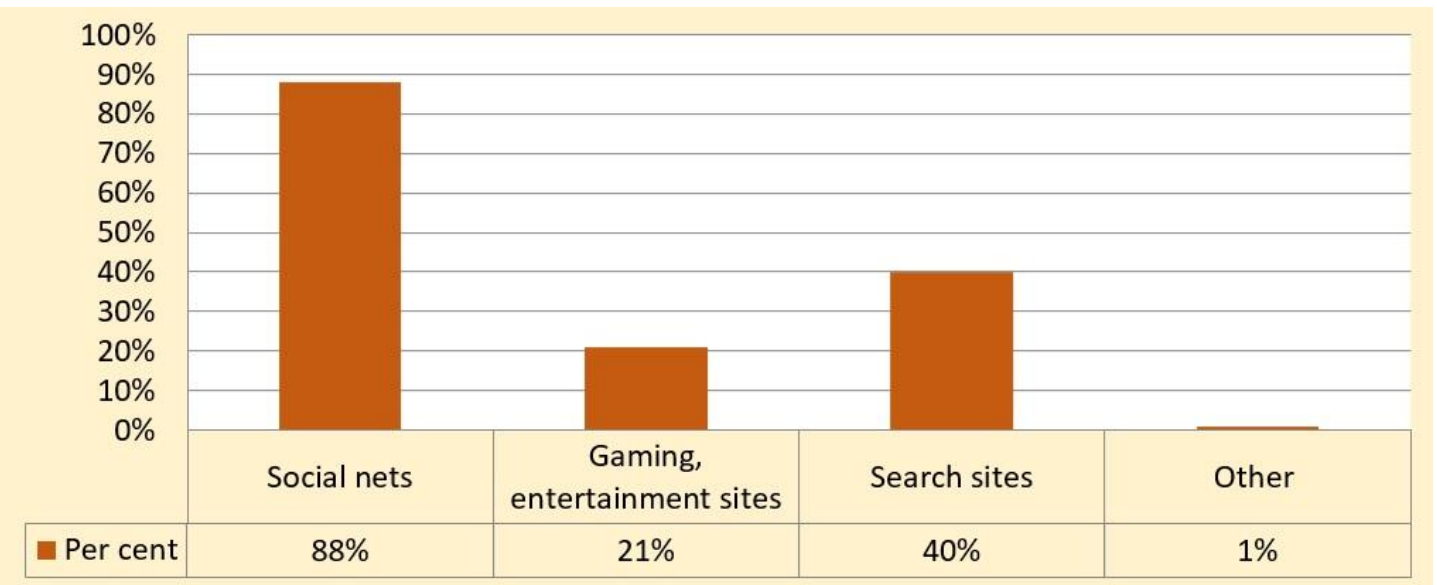

Figure 4: Internet Sites that Teenagers Prefer to Visit Source: Created by the Authors

One of the common concepts is internet surfing, which connects the idea of 'internet', the World Wide Web and the concept of 'surfing'. In the semantic content, it means 'to walk through the pages of internet sites. Paging can be unconscious, sometimes even meaningless, with a waste of one's own time. 


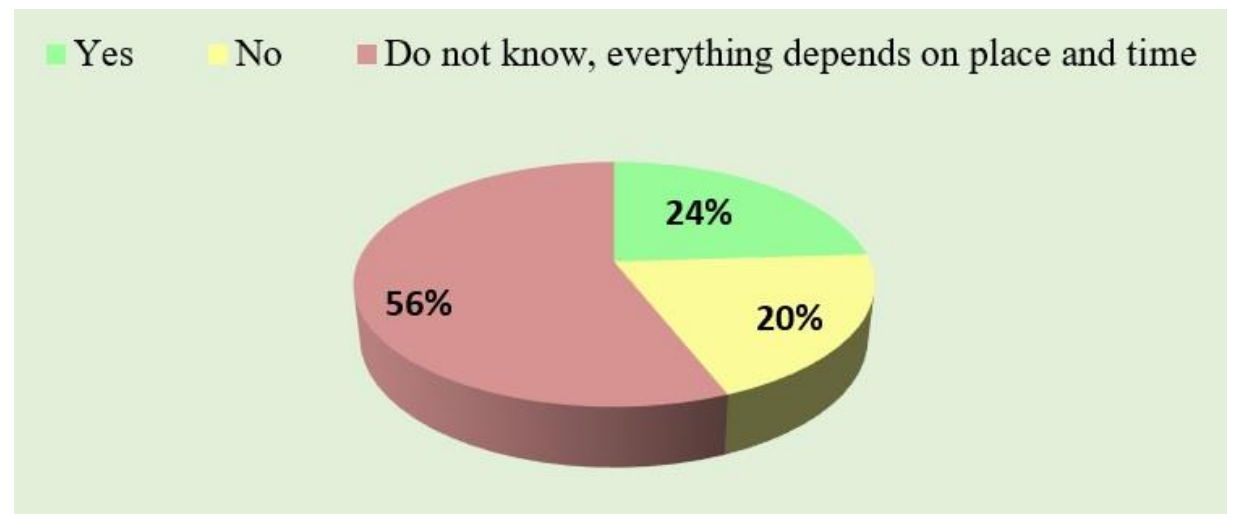

Figure 5: Do you prefer surfing the internet? Source: Created by the Authors

Our research unravelled that $24 \%$ of the teenagers have answered that they prefer internet surfing; for $56 \%$ of the respondents, internet surfing depends on the current location, time and subject's goal setting. It can be assumed that, for 56\%, internet connection might appear slow. Such a slow internet may result in accumulating irritation, fatigue, and a decrease in energy and efficiency (Figure 5).
In the multifunctionality of the internet, an educational function with the ability to choose an independent learning path plays a particularly significant role. Adolescents use the internet as fully as possible when performing school tasks, especially in writing essays, abstracts and other project activities, which is confirmed by the data in Table 2 -94\% of the respondents have given a positive answer to the question.

\section{Table 2: Do You Use the Internet to Prepare for Lessons?}

\begin{tabular}{|c|c|}
\hline No & Yes \\
\hline $4 \%$ & $94 \%$ \\
\hline Source: Created by the Authors
\end{tabular}

The third block of the questionnaire "Social The most popular social platforms among networks and adolescents" shows causal Kazakhstan teenagers are Vkontakte, Instagram, relationships between teenagers choosing social Facebook, Twitter, Odnoklassniki, as well as networks and their registration. instant messaging software applications: Periscope, Viber, and WhatsApp.

\begin{tabular}{|c|c|c|c|c|c|}
\hline Odnoklassniki & Vkontakte & Instagram & Facebook & Twitter & Other \\
\hline $15 \%$ & $95 \%$ & $85 \%$ & $43 \%$ & $23 \%$ & $0 \%$ \\
\hline
\end{tabular}

The research showed that $95 \%$ are registered in Vkontakte, $85 \%$ in Instagram, $43 \%$ in Facebook, the Odnoklassniki network is in the last place (Table 3, Figure 6). These platforms differ in content and purpose: some are designed to connect with friends, find communities, others from one-time to more extended communication, and others are divided by interests. Surprisingly, Facebook, according to a global study in 2018, had about 2 billion active users (Sergeeva, 2018).

Vkontakte social platform attracts with its democracy and possibilities of self-expression, its profiles are full of information; albums sort photos, and it is convenient to work with groups. Groups are peculiar clubs for hobbies. There are 12 content topics in this platform: personal information, films, music, literature, photos, 
desires, quotes, sex topics, obscene language, demonstration of addiction to alcohol and tobacco, drugs (Cheremisova, 2016).

The second popular platform is Instagram, that focuses on visual perception. Instagram's semiotic space includes graphics, logos, colours, photos, gestures and other visual images created

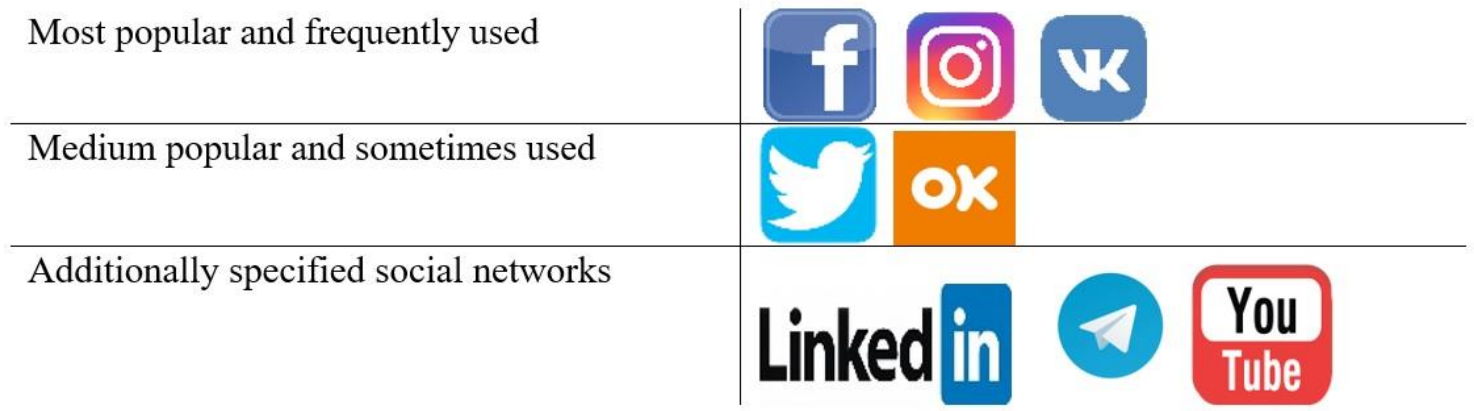

Figure 6: Social Networks used by the Teenagers Source: Created by the Authors by the users. Instagram is less communicative but more demonstrative and perceptionoriented. For those who are engaged in advertising and making money, this is an ideal social network. Practically, about $90 \%$ of the respondents are simultaneously registered in several social networks. (Table 4).

\section{Linked in $\triangle$ You}

\begin{tabular}{|c|c|c|c|c|c|}
\hline $\begin{array}{l}\text { Necessary } \\
\text { for } \\
\text { study/work }\end{array}$ & $\begin{array}{c}\text { For } \\
\text { communication } \\
\text { with friends }\end{array}$ & $\begin{array}{l}\text { Easy access } \\
\text { to media } \\
\text { files }\end{array}$ & $\begin{array}{l}\text { Boredom } \\
\text { and } \\
\text { loneliness }\end{array}$ & $\begin{array}{l}\text { All my friends } \\
\text { are } \\
\text { registered in } \\
\text { social } \\
\text { networks }\end{array}$ & Other \\
\hline $41 \%$ & $93 \%$ & $38 \%$ & $6 \%$ & $2 \%$ & $0 \%$ \\
\hline
\end{tabular}

The reasons for the uncontrolled registration of adolescents in social networks are shown in Table 4. For the majority of participants (93\%), the motivating reason for using social networks is the desire for communication; $41 \%$ respondents use it for professional needs; $38 \%$ for media accessibility and $6 \%$ of the respondents use it to overcome boredom and loneliness and only $2 \%$ use to chat with already registered friends. Communication with friends comes first, only then study.

At the same time, the dissonance is found in the results of the survey, for example; initially $94 \%$ of the respondents have stated that they actively use the internet when preparing for lessons, but the study has not been a reason for them to register. $93 \%$ of the respondents have chosen social networks for active communication. However, when answering the question "What 


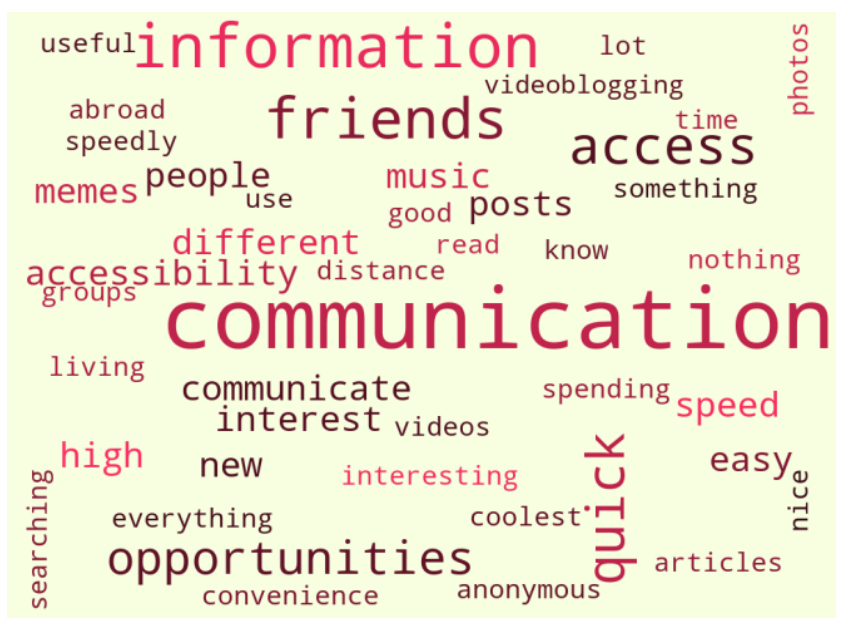

Figure 7: Results of the Words Cloud generator Source: Created by the Authors

The Words Cloud programme has generated all of the respondents' answers to the question: "What do you like most about social networks?" A visual image of the keywords of the questionnaire has been created. It includes the need for communication (meaning a lack of real communication), information about friends, etc. (Figure 7).

Table 5 demonstrates the results of the answers to the question: "What do you do in social networks?"

\begin{tabular}{|l|l|}
\hline Table 5: What Do You Do in Social Networks? & $71 \%$ \\
\hline Browsing other people's posts, photos of friends, acquaintances & $55 \%$ \\
\hline Putting "likes" under posts with photos, news & $85 \%$ \\
\hline Chatting with friends & $12 \%$ \\
\hline Reposting (sharing posts in the network) & $8 \%$ \\
\hline Sharing videos online & $5 \%$ \\
\hline Making money & $3 \%$ \\
\hline I am a professional blogger & $11 \%$ \\
\hline Commenting on posts & $1 \%$ \\
\hline All of the above & $1 \%$ \\
\hline Other & \\
\hline Source: Created by the Authors & \\
\hline
\end{tabular}

While $5 \%$ of the respondents make money online, $3 \%$ are bloggers, and a staggering $85 \%$ chat with friends, $71 \%$ browse other people's posts, and $55 \%$ of the respondents put "likes" under posts, which can be attributed to social surfing, misuse of a temporal resource.

The findings of our research also unravel that $84 \%$ listen to music in their free time (the ubiquitous image of digital generation in headphones). It is remarkable that $67 \%$ of the respondents meet with friends and $64 \%$ spend their free time with their family and almost as many $66 \%$ of the respondents surf the internet (Table 6).

Regardless of the geographical location (whether they are from a city or village), popular social platforms among teenagers are Instagram, YouTube, followed by Facebook, and Vkontakte. Almost all of them have accounts in social networks and use both mobile and home internet. The difference is observed in the frequency of access to the internet and the time frame: rural teenagers spend 24 hours on the Internet, while the urban teenagers up to 24 hours. The following facts can explain the former: 
- rural teenagers spend most of their time doing housekeeping, animal husbandry, and other other similar activities

- the attitude of the rural daily life;

- constant parental control.

\begin{tabular}{|l|l|}
\hline Table 6: How Do You Spend Your Free Time? \\
\hline Listening to music & $84 \%$ \\
\hline Meeting with friends & $67 \%$ \\
\hline Watching TV & $22 \%$ \\
\hline Surfing the Internet & $66 \%$ \\
\hline Reading books & $34 \%$ \\
\hline Doing sports & $38 \%$ \\
\hline Communicating with my family & $64 \%$ \\
\hline Doing household chores & $56 \%$ \\
\hline Doing nothing & $14 \%$ \\
\hline Shopping & $17 \%$ \\
\hline Source: Created by the Authors &
\end{tabular}

Source: Created by the Authors

For example, $17 \%$ of the interviewed teenagers from the village of Almalybak (Almaty region) have indicated that parents disconnect both home and the mobile internet every night.

Family values are characteristic for rural school children in the East Kazakhstan and Almaty regions, where the authority of parents or elder brothers/sisters is significant for them. 85\% assume to make their own family in the future. In the urban areas of Ust-Kamenogorsk and Almaty, for adolescents, both family and career are personal values. Urban teenager recognises either his/her own authority or that of a similar teenager (for example, a blogger who has achieved success). Plans and prospects for the digital generation of the two cities differ. In UstKamenogorsk, $50 \%$ of the respondents of Russian nationality plan to receive education in Russia or Germany in the future. They have friends in social networks (Vkontakte) from other countries, mainly from Russia, Ukraine and Germany. For Almaty, schoolchildren of the Nazarbayev Intellectual School have more ambitions and bigger plans for life than UstKamenogorsk teenagers. These teenagers are going to get higher education in universities abroad; while $25 \%$ have a desire to assist in the development of the Kazakh economy, they have patriotic feelings for their homeland, and 75\% realise themselves and build a career in
Kazakhstan. They are convinced that it is not enough just to obtain a diploma of higher education, they are interested in further training, extra educational courses, learning foreign languages, developing professional skills and abilities that will increase their competitiveness in the labour market.

Dynamic everyday life has attached modern society to different gadgets; the digital generations "are born with phones in hand". Of interest are the response to the question: "How will you react if you realise that you have left your smartphone at home?"

Rural teens have answered that the distance between the house and school is not big, they can quickly get back to the house. However, they have noted that nothing terrible might happen without a phone.

The city adolescents think that they will unconsciously reach into their pockets in search of a phone. At the same time, they will experience frustration, anxiety. Moreover, a teenager in a city without a smartphone is a problem for parents - loss of communication and control, fear for a child.

However, when asked what work they would choose - a steady income, an 8-hour working day in the office, or freelance (with a free schedule), then both rural and urban youth 
wanted stability and confidence in the future. That means that despite their multitasking skills and mental abilities, they lack confidence in themselves and their lives. Therefore, they need stability.

Narxoz University (Almaty, Kazakhstan) specialists have called the digital generation as "generation of low expectations" (Kaldygulova \& Kosnazarov, 2017: 3), and "generation born in an era of economic crisis", with the "loss of profit syndrome" or the problem of loneliness and fear of missing something important (Stillman \& Stillman, 2018: 22).

\section{Discussion}

An analysis of the behaviour of Kazakhstan teenagers shows the transformation of value orientations with the focus on the Western world. Researches of scientists from the USA, Germany, and Switzerland concerning the generation of "digital natives" (Prensky, 2001: 1) correlate with the researches of Russia and Kazakhstan. Digital generation $\mathrm{Z}$ is identified by criteria characterising everyday mentality, such as loneliness, absence of real-life communication, the diversity of virtual reality capabilities, ability to deal with information flows, media management tools, etc.

According to the research, Kazakhstan teenagers have two models of behaviour: model "I" and model "WE". "I" model is oriented towards selfdevelopment, independence, freedom of choice, freedom of speech, rights. On the other hand, there is the deeply rooted model "WE" that means belonging to the clan, "zhuz", traditions and customs of their families. Perhaps, that is why in social networks, it is easier to play the role of another person, to try on different communication practices.

\section{Conclusion}

The cultural/social media space of the digital generation is formed on the basis of digital technologies, presenting their visual worldview in images, signs and symbols. The content of the media space of Kazakhstan is shaped by the state policy on the implementation of the Digital Kazakhstan programme, approved by the Governmental Decree No. 827 as of 12/12/2017.
The Programme aims to accelerate the pace of economic development of the country due to the active introduction of digital technologies in all spheres of public life. The specified programme has provided accessibility of digital technologies, the involvement of Kazakhstan society in the social networks, including digital generation Z. Kazakhstan's cultural/social media space is represented by the format of a network social system, as evidenced by the results of the survey. The transformation of the society has an impact on the content of social platforms, on the daily life of adolescents, their communication skills, modernising their thinking and consciousness. It is important to note that the transformation of the value orientations of adolescents is influenced by the factor of the geography of residence and the ethnicity of adolescents, which is being witnessed in the survey results of the cities of Almaty and UstKamenogorsk. Digital media space causes problems of socialisation of adolescents living in the virtual world. However, despite the digitisation of their surroundings, family and family values are a priority for most adolescents. The digital identity of adolescents influences the formation of a national code, and, at the same time, lays the foundations of transparency and tolerance for the surrounding real world.

The lack of real youth communication with each other is a significant problem. Communication allows for experience exchange, growing up, mutual enrichment, self-knowledge and selfimprovement. In Kazakhstan, the year 2019 was declared the year of youth, which drew public attention to the problems of the youths. The researchers have developed several recommendations for working with young people:

- Strengthening the role of the family, family education, as the primary form of adolescent socialisation.

- Involving adolescents in activities that imply an exchange of interests, live communication and the achievement of specific results, for example, different hobby clubs. 
- Popularisation of Kazakhstan cultural values via social networks.

- Developing media competence approach in the pedagogical process.

\section{References}

Albert, D. (2015). Social Media in Music Education: Extending Learning to Where Students "Live". Music Educators Journal, 102(2), 31-38. doi:10.1177/0027432115606976

Baron, N.S. (2017). Reading in a digital age. Phi Delta Kappa, 99(2), 15-20. doi:10.1177/0031721717734184

Bolin, G. (2016). Media generations: experience, identity and mediatised social change.

Routledge.

Bhattacharyya, R. (2009). Examining the Changing Status and Role of Middle Class Assamese Women: Lessons from the Lives of University Students, Department of Geography, University of Newcastle. Retrieved from http://theses.ncl.ac.uk/jspui/handle/10443/303

Bourdieu, P. (2005). Social Space: Fields and Practices (pp. 576). St.Petersburg. Aletheia; M.: Institute of Experimental Sociology.

Carstensen, T. (2015). The Internet as Material Object in Social Practices: Recording and Analysis of Human-Internet Interactions. Nature and Culture, 10(3), 284-302.

doi:10.3167/nc.2015.100303

Cheremisova, I. (2016). Content Analysis of the Pages of Active Users of the Vkontakte social network. Vestnik of Volzhskyi State University. Series 11. Natural Sciences, 2(16), 74-80. doi:10.15688/jvolsu11.2016.2.9

Duncum, P. (2015). Digital Networking as a Creative Resource and Platform. Visual Arts Research, 41(2), 43-53.

doi:10.5406/visuartsrese.41.2.0043

Godik, Yu.O. (2011). Threats and Risks to the Safety of Child and Adolescent Audiences of New Media. "Mediascope" Electronic scientific journal, 2, 1-6.

Green, H., \& Hannon, C. (2007). Young people are spending their time in a space which adult find difficult to supervise or understand. Their
Space Education for digital generation (pp. 80). United Kingdom: Demos.

Inglehart, R., \& Welzel, K. (2011).

Modernization, cultural changes and democracy: The sequence of human development (pp. 12-13). M.: New Publishing.

Jussupov, M., Bozhkarauly, A., \& Rustembekova, D. (2018). Formation and Development of State Migration Policy. Journal of Advanced Research in Law and Economics, 9(5 (35)), 1643-1652. doi: 10.14505/jarle.v9.5(35).16

Kaldygulova, A., \& Kosnazarov, D. (2017). Gen Z. Five shades of the generation Z. Narxoz.

Business Review, 2(2), 10-17.

Levy, P. (1997). Cyberculture (pp. 222). Paris, Editions Odile Jacob.

Luhmann, N. (2005). The Reality of Mass Media (pp. 256). M.: Praxis.

Mannheim, K. (2000). Essays on the sociology of knowledge: The problem of generations competition - economic ambitions (pp. 162). M.: INION RAS.

Mead, M. (1983). Culture and the world of childhood. Selected Works (pp. 285). M. Maclay Institute of Ethnography, Ethnographic Library Series. Moscow: Nauka.

Montgomery, K. (2000). Children's Media Culture in the New Millennium: Mapping the Digital Landscape. The Future of Children, 10(2), 145-167. doi:10.2307/1602693.

Sparks \& Honey (2015). Meet generation Z: forget everything you learned about millennials (pp. 46). Retrieved from https://www.slideshare.net/sparksandhoney/g eneration-z-final-june-17

Mesch, G. (2009). The Internet and youth culture. The Hedgehog Review, 11(1), 50-53.

Nair, P. (2016). The Indian Child: Growing Young, Urbane and Liberal with Digital Games. Indian Anthropologist, 46(1), 79-92.

Oldenburg, O. (1999). The great good place (pp. 67). New York: Marlowe\&Company. 
Owen, S. (2018). The Gen Z equation, WGSN Project, Digital Media \& Marketing. Retrieved from https://www.wgsn.com/blogs/wgsn-lookgen-z-equation/

Palfrey, J., \& Gasser, U. (2011). Children of the digital era (pp. 368). M.: Eksmo.

Parsons, T. (2002). On social systems (pp. 832). M.: Academic project.

Pochebut, L. (2012). Cross-cultural and ethnic psychology: Study Guide (pp. 245). St. Petersburg: Peter.

Popovkin, A.V., \& Popovkina, G.S. (2019). Healing by Logos: Christian Aspects of Certain Modern Psycho-Pedagogical Practices. The Education and science journal, 21(7), 143-163 (In Russian). doi:10.17853/1994-5639-2019-7143-164.

Prensky, M. (2001). Digital Natives, Digital Immigrants. On the Horizon MCB University Press, 9(5), 1-6. doi:10.1108/10748120110424816
Sergeeva, U. (2018). Social networks in 2018: global study. Retrieved from https://www.webcanape.ru/business/socialnye-seti-v-2018-goduglobalnoe-issledovanie

Shehabat, A., Mitew, T., \& Alzoubi, Y. (2017). Encrypted Jihad: Investigating the Role of Telegram App in Lone Wolf Attacks in the West. Journal of Strategic Security, 10(3), 27-53. doi:10.5038/1944-0472.10.3.1604

Shehabat, A., \& Mitew, T. (2018). Black-boxing the Black Flag: Anonymous Sharing Platforms and ISIS Content Distribution Tactics. Perspectives on Terrorism, 12(1), 81-99.

Stillman, D., \& Stillman I. (2018). Generation Z at work. How to understand and find common language (pp. 270). Translated from English. M.: Mann, Ivanov and Ferber.

Zhana Urpakh (2017). Retrieved on 01 January 2019 from, https://zhanaurpak.kz/nash-lider/ 